\title{
AVALIAÇÃO DA QUALIDADE FÍSICO-QUÍMICA EM BEBIDAS OBTIDAS A PARTIR DO CAJU (Anacardium occidentale L.)
}

\section{$\underline{\text { Dyana Carla Lima }^{1 *} \text {; Samuel Veloso Carneiro }}{ }^{1}$; Nathan Hargreaves Noguera ${ }^{1}$; Adriana Machado Nogueira'; Judá de Andrade Alves; Rafael Audino Zambelli'}

${ }^{1}$ Departamento de Engenharia de Alimentos, Centro de Ciências Agrárias/Universidade Federal do Ceará. Fortaleza -CE, Brasil, dyana.carla@gmail.com *Autor para correspondência

O caju é uma matéria-prima que tem apresentado grande importância econômica no Brasil nos últimos anos, principalmente devido à obtenção de grande variedade de produtos e do seu alto valor nutritivo. $\mathrm{O}$ processamento industrial pode alterar os componentes presentes naturalmente nesse fruto, afetando as suas propriedades sensoriais e físico-químicas. Com objetivo de estabelecer parâmetros de comparação entre os produtos de diferentes processamentos do caju, realizou-se a caracterização físico-química de polpas de caju (PC), néctar de caju (NC) e preparado sólido de caju (PSC), tendo-se o sumo do caju (SC) como padrão. As amostras foram submetidas às análises de acidez, pH e determinação de sólidos solúveis totais, de acordo com a legislação brasileira vigente. Nessa perspectiva, desenvolveu-se metodologias para a determinação das propriedades de índice de refração, desvio óptico, tensão superficial e condutividade elétrica. Os resultados comprovaram que a amostra de PC foi a mais ácida, apresentando um valor de 0,3160 \% de ácido cítrico, todavia não foi a que apresentou o maior teor de sólidos solúveis totais (10,25 ${ }^{\circ}$ Brix); enquanto a amostra com menor acidez e teor de sólidos foi a PSC. Observou-se que a amostra SC foi a que apresentou maior condutividade elétrica $\left(3414,02 \mu \mathrm{S} . \mathrm{cm}^{-1}\right)$ e menor tensão superficial $(37,9$ $\left.\mathrm{mN} . \mathrm{m}^{-1}\right)$. Tais valores podem ser justificados devido à maior quantidade de sais minerais e glóbulos de gordura presentes no SC, respectivamente, uma vez que tal amostra não foi submetida a qualquer processamento. Observou-se que a amostra de néctar de caju desviou o plano da luz polarizada em 22,20 o maior desvio dentre as amostras analisadas, indicando que esta é a que apresenta maior quantidade de carboidratos, devido à estrutura dessas macromoléculas, já que apresentam maior quantidade de carbono assimétrico em sua estrutura, confirmando os dados obtidos por refratometria. Assim, foi possível concluir que estabelecer comparações entre bebidas de caju a partir da polpa natural, preparado sólido, néctar de caju e suco extraído do caju puro é fundamental para entender os critérios de escolhas pelos consumidores.

Palavras-chave: processamento, propriedades físico-químicas, fruto tropical. 